\title{
Forensic and Pharmacognostic Study of Aristolochia ringens Stem
}

\section{Minari JB* and Idris MA}

Department of Cell Biology and Genetics, University of Lagos, Nigeria

\begin{abstract}
Aristolochia ringens is considered as a local stimulant which could influence criminal behavior. In the present investigation, the detailed pharmacognostic study of $A$. ringens stem is carried out to lay down the standards, which could be useful in future Forensic identification of unknown plant material. The study includes macroscopic, microscopic, prelimimary phytochemical screening and physiochemical evaluation. The objective of this study was to characterize the unknown plant material seized from the scene of crime. In the present study, a TLC-method was described for the identification of $A$. ringens stem.
\end{abstract}

Keywords: A. ringens stem; Stimulant; Pharmacognostics; TLC; Macroscopy

\section{Introduction}

Aristolochia is a large plant genus with over 500 species. The scientific name Aristolochia was developed from Ancient Greek

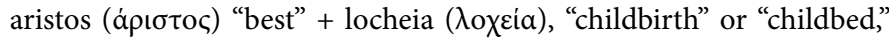
Collectively known as birthworts, pipevines or Dutchman's pipes, they are the namesake of the family (Aristolochiaceae). They are widespread and occur in the most diverse climates. Aristolochia ringens is one from the 500 species of Aristolochiaceae family with common name Gaping Dutchman's Pipe (pipe vine) which is a plant that is native to Brazil and is now been cultivated throughout the tropical world. The species name ringens means snarlping in Latin. Aristolochia ringens is a tall, hairless slender twiner plant with stalked leaves, round, almost kidneyshaped, pale green above, glaucous beneath plant. They are commonly found at the Southern-Eastern part of Nigeria [1] with the local name 'Akoogun' or 'Awo igba arun oyo'. The simple leaves are alternate and cordate, membranous, growing on leaf stalks. The plants are aromatic and their strong scent attracts insects. Stipules are noticeably leaflike, 2-lobed, kidney-shaped (Figure 1). Flower stalk is slender, four times as long as the leaf stalk with 7-10 inches long of flower, greenish and marked with dark purple. Aristolochia has been shown to be both a potent carcinogen and kidney toxin. Herbal compounds containing Aristolochia are classified as a Group 1 carcinogen by the International Agency for Research on Cancer [2,3]. The Flower has an obovoid sack, 2.5 inches long, woolly inside. The flower tube ascends obliquely from the sack, dividing into two very long lips. The two lips give an

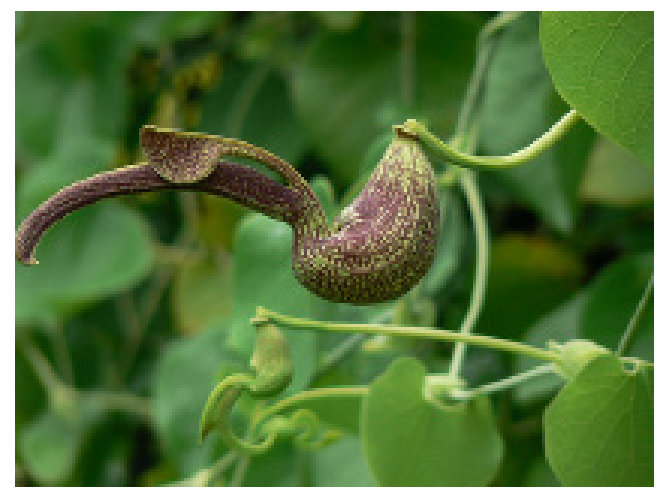

Figure 1: Aristolochia ringens Source: (NNMDA, 2008). impression of a gaping mouth. Due to their spectacular flowers, several species are used as ornamental plants. Epidemiological and laboratory studies have identified Aristolochia to be a dangerous kidney toxin; Aristolochia has been shown to be associated with more than 100 cases of kidney failure $[4,5]$. It has been confirmed that naturally occurring carcinogenic compounds have been found in plants within the genus Aristolochia as of 2013 [6]. In traditional Chinese medicine Aristolochia species are used for certain forms of acute arthritis and edema [7-9]. It's an example of medicinal plant with the methanolic extract of the whole plant commonly used in the traditional treatment of various diseases in humans and animals by some phytotherapist in Nigeria, and was evaluated for anti-trypanosomal efficacy in mice infected with Trypanosoma congolense [10]. A. ringens serves as an antidote for snake bite, used as an ornamental due to their spectacular flowers. Herb sellers at Adeleye market, Bariga, Lagos State and Herb sellers at Oke Aje market, Ijebu Ode, Ogun State use the decoction of $A$. ringens in combination with Picralina nitida seed as stimulant for men and it is the major plant. An individual on such stimulating plant could act under influence to commit crime just like any one under the influence of drugs like Yohimbine [11] and alcohol [12]. Although there are scientific means of identifying most stimulants but the standard for most local stimulants are readily unavailable. Therefore, in the present study an attempt has been made to study the pharmacognostic standards of the stem of $A$. ringens for forensic detetion when found at a crime scene as an unknown plant. These standards are of utmost importance not only in finding out the genuity, but also in the detection of adulterats in marketed drugs as well as in Forensic detection.

\section{Materials and Methods}

The dried sample of Aristolochia ringens stem was procured from a herb seller from Oke aje Market Ijebu-Ode, Ogun State, Nigeria and authenticated at Herbarium, University of Lagos, Nigeria with voucher number specimen (LUH 5570). It was well dried for (10 mins) in a microwave LG $450 \mathrm{~W}$ and ground with a manual bona vegetable

*Corresponding author: Minari JB, University of Lagos, Cell Biology Cell, Yaba Lagos-100001, Nigeria, Tel: +2348032488513; E-mail: baminjoe@yahoo.co.uk

Received November 06, 2014; Accepted November 20, 2014; Published November 24, 2014

Citation: Minari JB, Idris MA (2015) Forensic and Pharmacognostic Study of Aristolochia ringens Stem. J Forensic Res 6: 257. doi:10.4172/2157-7145.1000257

Copyright: ( $) 2015$ Minari JB, et al. This is an open-access article distributed unde the terms of the Creative Commons Attribution License, which permits unrestricted use, distribution, and reproduction in any medium, provided the original author and source are credited. 
Citation: Minari JB, Idris MA (2015) Forensic and Pharmacognostic Study of Aristolochia ringens Stem. J Forensic Res 6: 257. doi:10.4172/21577145.1000257

Page 2 of 4

\begin{tabular}{|c|c|c|}
\hline S. No. & Phytochemical component & Aqueous extracts \\
\hline 1 & Alkaloids & + \\
\hline 2 & Phenolics & + \\
\hline 3 & Phytosteroids & + \\
\hline 4 & Cardiac glycosides & + \\
\hline 5 & Saponins & + \\
\hline 6 & Phlobatanins & - \\
\hline 7 & Triterprenes & + \\
\hline 8 & Flavonoids & + \\
\hline
\end{tabular}

Table 1: Phytochemical Screening of aqueous extract of $A$. ringens Detected $=+$ Not detected $=-,{ }^{* *}$ Nitrate present.

\begin{tabular}{|c|c|c|c|}
\hline \multirow{2}{*}{ Content physio-chemical analysis } & \multicolumn{2}{|c|}{ Result (in \%) } & \multirow{2}{*}{ Average } \\
\cline { 2 - 3 } & $\mathbf{S 1}$ & $\mathbf{S 2}$ & \\
\hline Total Ash & 13.3 & 10.85 & 12.075 \\
\hline Acid insoluble ash & 7.5 & 6.35 & 6.925 \\
\hline Water insoluble ash & 10.85 & 7.0 & 8.925 \\
\hline Sulphated ash & 17.05 & 15.35 & 16.2 \\
\hline
\end{tabular}

Table 2: Physio Chemical Analysis of the powdered Aristolochia ringens stem.

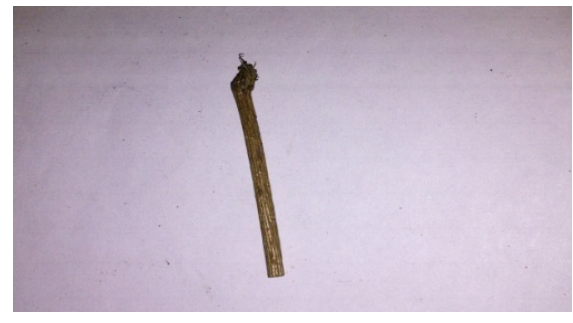

Plate 1: The twig part of $A$. ringens.

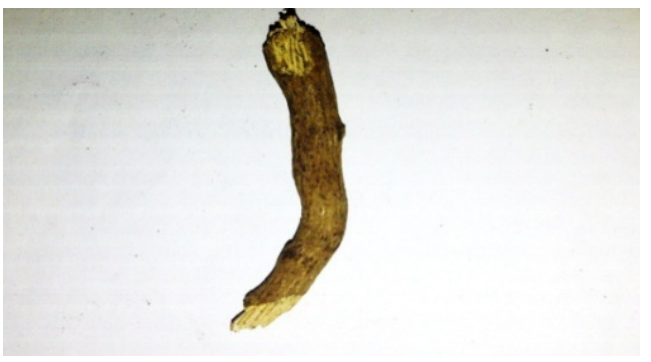

Plate 2: The woody part of $A$. ringens.

grater with cover. The ground specimen was stored in a clean glass ware container until needed for analysis.

\section{Chemicals}

All reagents used were analytical grade and were prepared in all glass distilled water.

\section{Qualitative phytochemical screening}

Phytochemical analysis of the aqueous extract was carried out following the methods described by Odebiyi and Sofowora (1978) $[13,14]$

\section{Nitrate test}

Nitrate test of the extract of $A$. ringens from phytochemical extract was carried out following the methods described by Mascetta (2002). [15] (Table 1).

\section{Physio chemical analysis}

An exhaustive Pharmacognosy was carried out using the standard methodology [14] (Table 2).

\section{Heavy metal determination (Lead)}

An exhaustive heavy metal analysis was out using the principle of Atomic Absorption Spectroscopy (AAS) analysis obeying Beer -Lambert Law [15].

\section{Macroscopic Study}

Plant sample was observed with the aid of the naked eyes under a white light.

\section{Powder microcsopy}

Two grammes of powdered $A$. ringens was weighed accurately in a test tube and boiled with $50 \% \mathrm{HNO}_{3}$. A pinch of $\mathrm{KCLO}_{3}$ was added to it, and then placed in sunlight for four days until the chips turn milky yellow. It was washed with water, then the powder was transferred on a clean microscopic glass slide. Lignified fibers were stained with the staining agent (safranin) and glycerin. The slide was observed under low power. The uniseriate medullary rays running straight and parallel occasionally becoming slightly curved, starch grains, lignified fibers, fragmented stem tissues and other characteristics were observed.

\section{Thin Layer Chromatographic (TLC) analysis}

Aliquot of standard Aristolochia ringens extract was obtained in Methanol (3.0 gm of powdered drug was extracted with methanol $(3 \times$ $15 \mathrm{ml}$ ) under reflux in a water bath). Extract was filtered and the volume was made up to $25 \mathrm{ml}$ with methanol. This extract was spotted onto a pre coated TLC plate silica gel G254, and developed with Toluene: Ethyl acetate: Formic Acid (5:5:2) and Acetic acid : Methanol (40:60) respectively in a pre-saturated TLC chamber, to the height of $9 \mathrm{~cm}$. Plate was removed from the chamber, dried in air and visualized under ultraviolet light at $254 \mathrm{~nm}$.

Similarly, TLC was also carried out on a pre-coated silica gel G254 plate by using Caffeine powder, Brucine powder and Rawulfia plant sample as reference standards. Then the plate was developed with Methanol: Chloroform (10:10). Standard solutions were prepared by dissolving $1 \mathrm{mg}$ each of Caffeine powder, Brucine powder and Rawulfia plant samples in $10 \mathrm{ml}$ of methanol. $10 \mathrm{nl}$ each of the test and standard solutions were taken on a TLC plate as bands of $10 \mathrm{~mm}$. The plate was developed to a distance of $8 \mathrm{~cm}$ from the line of application. Then the plate was dried in air and was visualized under ultraviolet light at 254 nm.

\section{Results and Discussion}

\section{Macroscopic examination (Plates 1 and 2)}

The plant sample comprises of two parts, the twig (soft) and the woody part (strong). The twig which is slender, golden brown in colour with striate epidermis down the entire length of it is shown in Plates 1 and 2. Sample size $5.2 \mathrm{~cm}$ in length and $0.3 \mathrm{~cm}$ diameter. Plates $3 \mathrm{a}$ and $3 \mathrm{~b}$ shows a brown woody part of the plant with dehydrated epidermis thus shrinkle. Vascular bundle evidence from the cut-end and stipule bi-loop was also observed. Sample size $5.7 \mathrm{~cm}$ in length and diameter $0.9 \mathrm{~cm}$ was considered.

A band of $6.8 \mathrm{~cm}$ was observed under $254 \mathrm{~nm}$ UV light. The chromatogram obtained from the test sample solution against the standards solution shows a band at $\mathrm{Rf}$ at 00.86 for test sample 
Citation: Minari JB, Idris MA (2015) Forensic and Pharmacognostic Study of Aristolochia ringens Stem. J Forensic Res 6: 257. doi:10.4172/21577145.1000257

Page 3 of 4

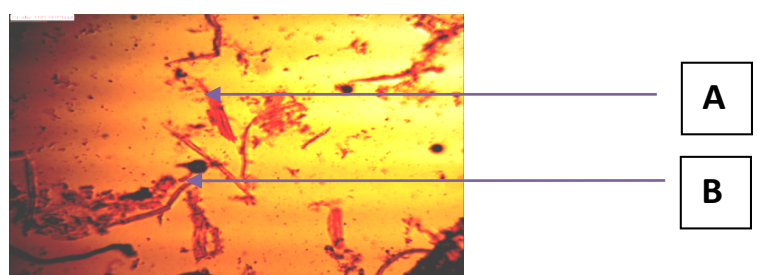

Plate 3a: Microscopic view of Aristolochia ringens powder showing lignified fibers $(A)$ and starch $(B)$.

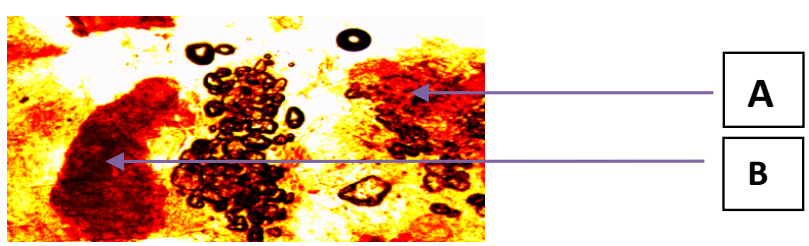

Plate 3b: Microscopic view of Aristolochia ringens powder showing fragmented stem tissue $(A$ and $B)$.

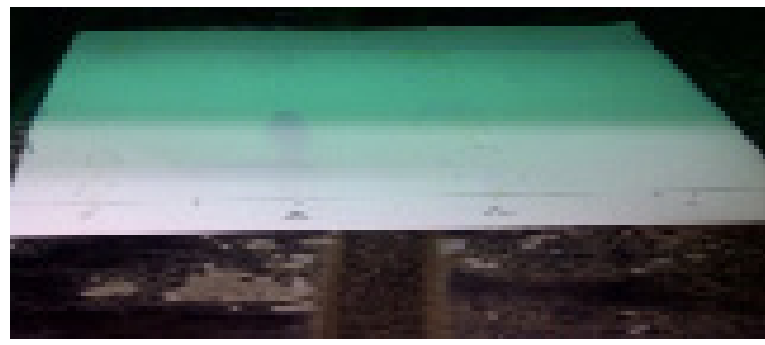

Plate 4: Test and standard solution TLC plate of methanolic extracts before spraying with dragendoff.

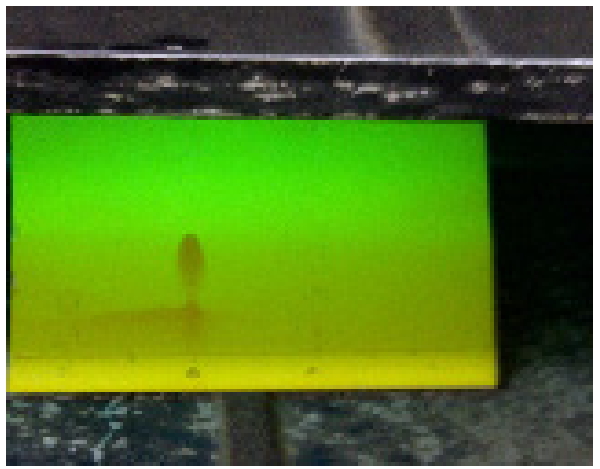

Plate 5: Test and standard solution TLC plate of methanolic extracts after spraying with dragendoff.

corresponding to that of the standards. The plate was then sprayed using dragendoff spray for clear bands visualization.

The photographic pictures of the test and standard solution TLC plates before and after spraying with dragendoff are shown in Plates 4 and 5. A common band with brucine (B) and rawulfia (R) standards at $3.2 \mathrm{~cm}$ under $254 \mathrm{UV}$ light before the plate was sprayed with dragendoff was observed. A clear and visible band from A. ringens (A) to brucine (B) clear and visible band from $A$. ringens to brucine was observed after spraying the TLC plate with dragendoff. Also a visible movement was also observed for brucine from the point of spot to $6.4 \mathrm{~cm}$. The common band was not clear again after spray. Table 6 , shows all the noticeable band of the test and standard solution from the point of spot to the solvent font in $\mathrm{cm}$ (Plates 4 and 5).

In the present study an attempt has been made to select some Physiochemical, Phytochemical, Macro and Microscopic and Thin Layer Chromatography examinations, which are found to be very useful tools for the identification and characterisation of $A$. ringens stem. A simple and precise analytical method is used for the analysis of

\begin{tabular}{|c|c|}
\hline Tests & Result (in $\mathbf{~ m g / g )}$ \\
\hline Ethanol & 160 \\
\hline Methanol & 146 \\
\hline Pet ether & 161 \\
\hline Extractive Values & 15 \\
\hline Alcohol soluble extractive value & 10 \\
\hline Water soluble extractive value & \\
\hline
\end{tabular}

Table 3: Alcohol insoluble ash analysis yield and extractive values of powdered $A$. ringens obtained.

\begin{tabular}{|c|c|}
\hline Extractive value & Percentage \\
\hline Ethanol & 16 \\
\hline Aqueous & 8.925 \\
\hline Pet ether & 16.1 \\
\hline Methanol & 14.6 \\
\hline Ash & $<13$ \\
\hline Heavy metal lead & $6.3 \mathrm{ppm}$ \\
\hline Acid insoluble ash & $<10 \mathrm{w} / \mathrm{w}$ \\
\hline
\end{tabular}

Table 4: Physicochemical Evaluations of $A$. ringens.

\begin{tabular}{|c|c|c|}
\hline S. No. & Solvent system used & Rf value \\
\hline \multirow{7}{*}{1.} & \multirow{7}{*}{ Toluene :Ethyl acetate :Formic acid $(5: 5: 2)$} & 0.755 \\
\hline & & 0.788 \\
\hline & & 0.822 \\
\hline & & 0.888 \\
\hline & & 0.911 \\
\hline & & 0.96 \\
\hline & & 0.97 \\
\hline \multirow{5}{*}{2} & \multirow{5}{*}{ Methanol : Chloroform (10:10) } & 0.085 \\
\hline & & 0.725 \\
\hline & & 0.85 \\
\hline & & 0.943 \\
\hline & & 0.863 \\
\hline \multirow{5}{*}{3} & \multirow{5}{*}{ Acetic acid: Methanol (40:60) } & 0.887 \\
\hline & & 0.943 \\
\hline & & 0.987 \\
\hline & & 0.925 \\
\hline & & 0.975 \\
\hline
\end{tabular}

Table 5: TLC data of $A$. ringens.

\begin{tabular}{|c|c|c|c|c|}
\hline Bands (cm) & A. ringens (A) & Brucine (B) & Rawulfia (R) & Caffeine (C) \\
\hline 1. & 0.7 & 0.6 & 0.7 & - \\
\hline 2. & 1.8 & - & 1.7 & - \\
\hline 3. & - & 3.2 & 3.2 & - \\
\hline 4. & 5.8 & - & - & - \\
\hline 5. & - & 6.4 & 6.5 & - \\
\hline 6. & 6.8 & 6.7 & 6.7 & \\
\hline 7. & 6.9 & 6.9 & 6.9 & 6.9 \\
\hline 8. & 7.55 & - & - & - \\
\hline
\end{tabular}

Table 6: Bands of methanolic extracts of test and standards solutions from point of spot $(\mathrm{cm})$. 
Citation: Minari JB, Idris MA (2015) Forensic and Pharmacognostic Study of Aristolochia ringens Stem. J Forensic Res 6: 257. doi:10.4172/21577145.1000257

A. ringens stem, which could be useful in future forensic identification of unknown plant material (Tables 1-6).

The information and identification of some local stimulants are not readily available. It is found that the Physiochemical, Phytochemical, Macro \& Microscopic, and TLC examination are very useful tools for the identification of $A$. ringens stem. Phytochemical studies were carried out for the identification of $A$. ringens stem. Thin Layer Chromatographic studies showed the presence of active principles of A. ringens using three different samples with a common phytochemical property i.e. Alkaloids, this is further suggested that the proposed methods are simple, sensitive and reproducible.

The suggested protocol can also be used for the qualitative evaluation of $A$. ringens stem in laboratory with very less equipemtns and expenses. These can be employed successfully for routine forensic analysis of $A$. ringens. As the evaluation expenses are less as compared to other instrumental methods, this could be a method of choice for official monographs in forensic Toxicology.

\section{Conclusion}

These distinct pharmacognosic properties of Aristolochia ringens stem observed from the above studies shows that, it can easily be characterized and identified when obtained as unknown plant from crime scene during forensic detection.

\section{References}

1. Nigerian Natural Medicine Development Agency (NNMDA) (2008) Medicinal plants in South-East Nigeria. 1: 21.

2. Grollman AP, Brdar B, Slade N, Turesky RJ, Goodenough AK, et al. (2007) Aristolochic acid and the etiology of endemic (Balkan) nephropathy. Proceedings of the National Academy of Science 104: 12129-12134.

3. American Cancer Society (ACS (2006) Known and Probable Carcinogens (Including Industrial Processes, Occupational Exposures, Infectious Agents, Chemicals, and Radiation).
4. Chen, Chung-Hsin, Kathleen G, Dickman, Masaaki, et al. (2012) Aristolochic acid- associated urothelial cancer in Taiwan. Proceedings of the National Academy of Sciences 109: 8241-8246.

5. Cosyns JP (2003) Aristolochic acid and 'Chinese herbs nephropathy': a review of the evidence to date. Drug Saf 26: 33-48.

6. Williams R (2013) Cancer- Causing Herbal Remedies: A potent carcinogen lurks within certain traditional Chinese medicines.

7. Freeman-Mitford A B (1992) The Bamboo Garden (1896) quoted in Alice M Coats, Garden Shrubs and Their Histories (1964), s.v. "Aristolochia".

8. Vanherweghem JL, Depierreux M, Tielemans C, Abramowicz D, Dratwa M, et al. (1993) Rapidly progressive interstitial renal fibrosis in young women: association with slimming regimen including Chinese herbs. The Lancet 341 387-391.

9. Depierreux M, Van Damme B, Vanden Houte K, Vanherweghem JL (1994) Pathologic aspects of a newly described nephropathy related to the prolonged use of Chinese herbs. Am J Kidney Dis 24: 172-180.

10. Osho IB and Lajide L (2013) Antitrypanosomal activity of Aristolochia ringens against Trypanosoma congolense infection in mice. Journal of Pharmacognosy and Phytotherapy 6: 1-3

11. National Council on Alcoholism and Drug Dependence (NCADD) (2010) Alcohol, drugs and crime. Accessed 31st December, 2013.

12. Odebiyi A and Sofowora AE (1978) Phytochemical screening of Nigerian Medicinal Plants. Part III. 4: 234-246.

13. Sofowora A (1993) Medicinal Plants and Traditional Medicine I Africa. 2nd edition. Spectrum Books Limited (Publisher), Ibadan, Nigeria, 400.

14. Mascetta, Joseph A (2002) Barron's How to Prepare for the SAT II: Chemistry 7th edition. Barron's Educational Series, Inc. 808.

15. The Ayurvedic Pharmacopoeia of India (1999) New Delhi, Government of India Ministry of Health \& Family Welfare, Dept. of Indian Systems of Medicines \& Homeopathy. 1st ed. Part 1 (II): 17-18. 